Article

\title{
Psychopathy, Machiavellianism and Parental Behavior: A Correlational Study Modulated by Gender
}

\author{
Polett Bali 1,* and Guillaume Durand 2,* \\ ${ }^{1}$ Department of Clinical Psychological Science, Maastricht University, P.O. Box 616, Maastricht 6200 \\ MD, The Netherlands \\ ${ }^{2}$ Department of Psychiatry \& Neuropsychology, Maastricht University, P.O. Box 616, Maastricht \\ 6200 MD, The Netherlands \\ *Correspondence: polett.bali@gmail.com (P.B.); gdura061@uottawa.ca (G.D.)
}

\begin{abstract}
Psychopathy and Machiavellianism are two components of the Dark Triad including personality traits such as egoism, coldheartedness and deceitfulness. While psychopathy and Machiavellianism possess some etiological differences, prior investigations showed similarities regarding the onset of these personality traits, namely in the field of parental behavior. The present study investigated potential correlations between psychopathy and Machiavellianism traits in adulthood, alongside reports of parental behavior during childhood. A community sample from Hungary $(N=70)$ was recruited and completed the Machiavellian Personality Scale (MPS), the Mach-IV inventory (Mach-IV), the Self-Report Psychopathy Scale (SRPS) and the Short-EMBU (sEMBU). No strong correlations were found between parental behaviors and psychopathy or Machiavellianism. However, positive correlations were found between the Machiavellian measures and the measures of psychopathy by subtypes. Analysis of the gender differences between the psychopathy and Machiavellianism revealed a positive correlation for primary psychopathy and Machiavellianism for both gender, as well as a positive correlation between secondary psychopathy and Machiavellianism for males only. Results are explained in terms of gender differences in socialization. Further implications and limitations are discussed.
\end{abstract}

Keywords: psychopathy; Machiavellianism; parental style; gender differences; socialization theories

\section{Introduction}

Among the myriad of personality traits negatively influencing social interactions, psychopathy and Machiavellianism stand out of the lot due to their hostile characteristics. Despite many similarities between these two constructs, such as tendencies to be deceitful, egoistic, hypercompetitive and coldhearted, both personality traits possess their respective characteristics (Ali \& ChamorroPremuzic, 2010; Berg et al., 2013). The central components of psychopathy are high levels of impulsivity and thrill seeking, along with low levels of empathy and anxiety, while the central component of Machiavellianism is a high level of manipulation (Paulhus \& Williams, 2002). Since psychopathy possesses multiple central components, further sub-divisions were done on the 
construct.

Karpman (1941) proposed to divide the concept in two subtypes, namely primary and secondary psychopathy. Primary psychopaths (Factor 1) are considered to be manipulative, selfish, fearless, emotionally stable and socially potent. In contrast, secondary psychopaths (Factor 2) are antisocial, emotionally unstable, impulsive, and display high levels of blame externalization (Berg et al., 2013). Following this distinction, the Psychopathy Checklist and its revised version (PCL, PCL-R) were created as diagnostic tools for the two factors of psychopathy, using incarcerated inmates and institutionalized individuals for its development (Hare, 1991, 2003). While the PCL was initially developed on the population of criminal offenders, its usage outside of the criminal settings is limited due to the focus on criminal behaviors related to psychopathy, which is inconsistent with some alternative point of views (Hall \& Benning, 2006; Ray, Weir, Poythress, \& Rickelm, 2011). Initial conceptions of psychopathy stated that psychopaths can be found in the community, although this is not a certain gage of their criminal tendencies (Cleckley, 1941). In order to assess psychopathic tendencies in the community, an alternative tool was developed. The SelfReport Psychopathy Scale (SRPS), designed on the PCL criteria, can identify highly psychopathic individuals in non-institutionalized samples (Levenson, Kiehl, \& Fitzpatrick, 1995). The two-factor model is still prominent in the SRPS, primary psychopathy assessing "selfish, uncaring, and manipulative attitudes toward others" and secondary psychopathy assessing "impulsivity and selfdefeating lifestyle" (Levenson et al., 1995).

The lack of consensus regarding the personality traits related to psychopathy stems from the debate on genetic versus environmental factors. According to Frick, Bodin, and Barry (2000), a number of studies found evidences supporting a combination of both biological and environmental factors to be responsible for the development of psychopathic traits in youth. Levenson et al., (1995) contradicted this theory and proposed arguments in favor of a central role from social learning rather than biology in psychopathic behaviors. Psychopathic personality was later described in detail through three distinct components: behavioral, interpersonal, and affective characteristics (Hart \& Hare, 1998). Behaviorally, a psychopathic trait should include risk-taking, sensation seeking, and impulsivity. Interpersonally, a psychopathic trait should include grandiosity, egocentricity, manipulation, and arrogance. Affectively, a psychopathic individual is unable to form strong emotional bonds and has shallow emotions.

Deficiencies in emotional bonding can be observed in children manifesting early psychopathic tendencies. Early exposure to dysfunctional family environments can influence a child's personality toward the development of psychopathic traits (Belsky, Steinberg, \& Draper, 1991; Saltaris, 2002). Among other familial dysfunctionalities, the lack of discipline has been related to an increase of antisocial behaviors in adulthood (Klonsky, Oltmanns, Turkheimer, \& Fiedler, 2000; Robins, 1966). The lack of parental discipline toward their children could stem from stress levels of the parents themselves. Previous investigations concluded that distressed parents use unstable and unsuccessful parenting methods, which worsens their children's behavioral problems (Fite, Greening, \& Stoppelbein, 2008; Patterson, 1988). Further investigations revealed that 
parenting stress relate with the callous and unemotional trait, which is one of the hallmark of the psychopath characteristics (Fite et al., 2008). Moreover, when considering the different parental stress dimensions, the authors concluded that attachment difficulties and role restrictions were also related to psychopathic traits.

Together with the early emergence of psychopathic traits, children from inadequate environments are also prone to developing higher levels of Machiavellianism (Sutton \& Keogh, 2001). The degrees to which an individual lacks morality and is prone to manipulate other individuals define the degree of Machiavellianism (Christie \& Geis, 1970). Machiavellians' cynical attitude about human nature includes being unemotional in personal relations and uncommitted to goals (Sutton \& Keogh, 2001). Moreover, a Machiavellian individual has a desire to reach a high status, and will practice control over anyone in his environment (Dahling, Whitaker, \& Levy, 2008). Another aspect of Machiavellianism is a general distrust and negative perception of other individuals (Christie \& Geis, 1970). Moreover, Machiavellian individuals also assume that others have the same point of views and exhibit similar behaviors (Dahling et al., 2008). These characteristics could emerge from parental behaviors. Two hypotheses support the role of the family environment: standard socialization hypothesis and the reciprocation hypothesis. According to the standard socialization, or modeling hypothesis, children try to follow their parents' example, and in the process identify with their ideology, along with their manipulative skills. The second hypothesis is the reciprocation, or victim hypothesis, which states that children will learn by doing rather than copying their parents' example (Kraut \& Price, 1976). Parents will succumb to their children's manipulative schemes, which will reinforce the manipulative behaviors in the child. These results support the idea that psychopathy and Machiavellianism partly stem from the same origin, namely the influence of parental behaviors.

Further similarities between psychopathy and Machiavellianism were investigated by Paulhus and Williams (2002). Together, they created the concept of the Dark Triad, including three personality traits: psychopathy, Machiavellianism, and narcissism (Jonason \& Webster, 2010). Previous research on the Dark Triad concluded that Machiavellianism and psychopathy were overlapping constructs when assessed in a normal population (Paulhus \& Williams, 2002). Machiavellianism is also considered by certain authors as a subclinical variation of psychopathy (Mealey, 1995). While evidences are pointing toward a correlation between Machiavellianism and psychopathy, it is unknown if this correlation is with the concept of psychopathy as a whole, or if it is only applicable to one of its subtypes. Primary psychopathy encompasses the interpersonal and emotional traits, which includes being manipulative and having no remorse, which are dominating traits in Machiavellianism as well. Investigation of the relationship between psychopathy and Machiavellianism will provide new insights on their link to one another. Furthermore, while assessing levels of psychopathy and Machiavellianism, it is important to take gender into consideration. Previous studies showed that psychopathy scores tend to be significantly higher in males than females (Hicks et al., 2012; Lee \& Salekin, 2010; Lilienfeld \& Hess, 2001). Similar results were reported between genders for Machiavellianism, where males scored significantly higher than females (Allsopp, Eysenck, \& Eysenck, 1991). 
The present study investigated the effect of early parental behaviors on psychopathy and Machiavellian expressions at a later stage of life, along with the relationship between the two later constructs. To this end, three hypotheses were formulated. First, we expected a statistically significant positive correlation between Machiavellianism, psychopathy and perceived parental behaviors, such as overprotection and rejection factors. Second, we expected a strong statistically significant positive correlation between Machiavellianism and primary psychopathy, as well as a weak significant positive correlation between the former and secondary psychopathy. Finally, we expected gender to play a role in the correlation between Machiavellianism and psychopathy.

\section{Method}

\subsection{Participants and Procedures}

All participants received informed consent and received a debriefing at the end of the study. A total of 45 males and 25 females $(N=70)$ between the ages of 24 and $58(M=32.01, S D=6.76)$ were recruited from a Hungarian community to take part in this study. All participants were full time employees. The experiment consisted of 4 questionnaires, which were adapted into an online format for easier distribution and access. Participation was completely anonymous. Participants did not receive any financial compensation for their participation in this study. This study has received ethical approval from the ethical committee of the University of Pécs and complies with all regulations.

\subsection{Materials}

Machiavellian Personality Scale (MPS; Dahling et al., 2008). The MPS is a 22-item self-report questionnaire assessing Machiavellian personality traits. The questionnaire is divided into four subscales, namely Amorality, Desire for Control, Desire for Status, and Distrust of Others. Each item is rated on a 5-point Likert scale. Validity studies of MPS provide evidence for adequate convergent, divergent and criterion-related validity of the questionnaire (Dahling et al., 2008).

Mach-IV inventory (Mach-IV; Christie \& Geis, 1970). The Mach-IV is a well-established tool for measuring Machiavellianism. The questionnaire consists of 20 items, which are rated on a 5-point Likert scale. It is designed to reveal Machiavellian views and tactics used for manipulating other people. The total score of all 20 items with the addition of 20 constitutes the final score. The MachIV has been used in several studies, and shows constant adequate reliability (Christie \& Geis, 1970; Paulhus \& Williams, 2002).

Self-report Psychopathy Scale (SRPS; Levenson et al., 1995). The SRPS is a 26-item self-report scale for assessing psychopathy on a 4-point Likert scale. The measure contains two distinct factors: primary and secondary psychopathy. Primary psychopathy scale measures the "callous/manipulative interpersonal style", and the secondary psychopathy scale measures "behavioral problems like impulsivity and a self-defeating behavior". These factors correspond to the PCL-R initial factors and shows adequate reliability and validity (Brinkley, Schmitt, Smith, \& 
Newman, 2001; Harpur, Hare, \& Hakstian, 1989).

Short-EMBU (s-EMBU; Arrindell et al., 1999). The s-EMBU is a 23-item questionnaire, derived from the original 81-item version, and is used for assessing the perceived parental rearing behavior on a 4-point Likert scale. Participants responded to the questionnaire twice, once in relation to their father's behavior and once in relation to their mother's behavior. The s-EMBU is divided in three factors, namely Rejection, Overprotection, and Emotional Warmth. The short version of the questionnaire was subsequently validated internationally, providing a reliable alternative to its extended version (Arrindell et al., 1999; Arrindell et al., 2001).

\section{Results and Discussion}

The descriptive statistics for each scale alongside their respective internal consistencies are presented in the Table 1. The internal consistency for this sample was acceptable on the majority of the scales/inventories (from .70 to .83), and high for the primary psychopathy scale with Cronbach's alpha of .91. Comparing this sample's s-EMBU alpha coefficients with previous findings on the Hungarian sample reveals similar values (Arrindell et al., 1999). The current sample's Overprotection scale for father and mother are $\alpha=.70$, and $\alpha=.76$, respectively, while the internal consistency for the Hungarian population was $\alpha=.77$, and $\alpha=.78$, respectively. The Rejection subscale has alpha coefficient for father and mother, $\alpha=.79$, and $\alpha=.78$ respectively, and the Hungarian sample presents Cronbach's $\alpha=.72$, and $\alpha=.75$ (Arrindell et al., 1999).

Table 1.

Descriptive statistics and reliability coefficients (Cronbach's $\alpha)$ for different scales and subscales $(N=$ 70).

\begin{tabular}{lccc}
\hline \multicolumn{1}{c}{ Scale } & Mea & Standard Deviatior & Cronbach's $\alpha$ \\
\hline Primarv bsvchopathv & 1.82 & .49 & .91 \\
Secondarv psvchopathv & 1.75 & .40 & .72 \\
MPS & 54.16 & 10.21 & .83 \\
Mach-IV & 91.77 & 13.72 & .78 \\
Overprotection of father & 16.99 & 4.11 & .70 \\
Overprotection of & 19.90 & 4.68 & .76 \\
Reiection of father & 8.84 & 2.86 & .79 \\
Reiection of mother & 8.64 & 2.53 & .78 \\
\hline
\end{tabular}

All assumptions related to the proper use of correlation analyses were met. Pearson correlations were computed between the s-EMBU scales (focusing on the Rejection and Overprotection factors), MPS, Mach-IV, and the SRPS (primary and secondary psychopathy) scales, and are presented in the Table 2 . No statistically significant correlations were found between the parental behaviors as displayed by the Rejection and Overprotection scales when compared to the Mach-IV or the SRPS scales. One weak negative correlation was found between the MPS and the father's Rejection scales. These results do not support prior hypotheses regarding the role of parental behaviors and the display of psychopathic traits or Machiavellianism in adulthood (Marshall \& Cooke, 1999).

Table 2 . 
Correlations between the MPS, Mach-IV, Psychopathy Subscales and selected s-EMBU Subscales.

\begin{tabular}{|c|c|c|c|c|c|c|c|c|}
\hline Variable & 1 & 2 & 3 & 4 & 5 & 6 & 7 & 8 \\
\hline (1)MPS & - & & & & & & & \\
\hline (2)Mach-IV & $.75^{* *}$ & - & & & & & & \\
\hline (3)Primary & $.75^{* *}$ & $.79^{* *}$ & - & & & & & \\
\hline \multicolumn{9}{|l|}{ Psychopathy } \\
\hline (4)Secondary & .21 & $.37^{* *}$ & $.36^{* *}$ & - & & & & \\
\hline \multicolumn{9}{|l|}{ Psychopathy } \\
\hline (5)Rejection of father & $-.24^{*}$ & .01 & .07 & .18 & - & & & \\
\hline (6)Rejection of mother & -.06 & -.06 & .11 & .12 & $.44^{* *}$ & - & & \\
\hline $\begin{array}{l}\text { (7)Overprotection of } \\
\text { father }\end{array}$ & -.07 & -.01 & - & .06 & $.37^{* *}$ & .04 & - & \\
\hline $\begin{array}{l}\text { (8)Overprotection of } \\
\text { mother }\end{array}$ & -.03 & -.05 & - & .12 & .09 & $.31^{* *}$ & $.39 * *$ & - \\
\hline
\end{tabular}

Note. ${ }^{*} p<.05,{ }^{* *} p<.01$, two-tailed.

Despite the lack of strong correlations between parental behaviors and dark personality traits, a few positively strong correlations were found between the MPS, the Mach-IV and the SRPS. While it was expected for the two Machiavellianism scales to be strongly positively correlated to one another, it is interesting to examine the correlation between Machiavellianism and psychopathy. First, MPS displays a strong positive correlation with the primary psychopathy subscale (.75), but not with the secondary psychopathy subscale. Alternatively, Mach-IV shows a strong positive correlation with the primary psychopathy subscale (.79), as well as a weak positive correlation with the secondary psychopathy subscale (.37). Prior investigations in the Dark Triad revealed a weak correlation between the Mach-IV and the self-report psychopathy scale (SRP-III) (Paulhus, Neumann, \& Hare, 2010), with a correlation of .31, which is a weaker correlation than in the present study (Paulhus \& Williams, 2002). However, another study examining the Mach-IV and the SRPS found a strong positive correlation between Machiavellianism and primary psychopathy, alongside a moderate positive correlation between Machiavellianism and secondary psychopathy (Ali \& Chamorro-Premuzic, 2010). These results suggest that while the Mach-IV overlap on concepts related to both primary and secondary psychopaths, the MPS only focuses on traits related to primary psychopathy, such as manipulative behaviors. These results support theories from other researchers supporting the conceptual differences between Machiavellianism and psychopathy (Paulhus \& Williams, 2002; Vernon, Villani, Vickers, \& Harris, 2008; Williams \& Paulhus, 2004). The current results suggest a bigger overlap between Machiavellianism and secondary psychopathy when the former is assessed with the Mach-IV rather than the MPS.

In order to determine the influence of gender on correlations between Machiavellianism and psychopathy, further analyses were performed. Pearson coefficients are displayed in Table 3. As expected, both measures of Machiavellianism correlate highly with each other for both genders. It was also expected that both MPS and Mach-IV would be highly correlated with primary 
psychopathy for both genders. However, secondary psychopathy shows atypical results, where both MPS and Mach-IV are moderately correlated with secondary psychopathy exclusively in the male samples.

Table 3.

Correlations between the MPS, Mach-IV and Psychopathy subscales for males and females.

\begin{tabular}{lrr|rr} 
& \multicolumn{2}{c|}{1.} & \multicolumn{2}{c}{2.} \\
\cline { 2 - 4 } & Male & Females & Males & Females \\
\hline (1)MPS & & & & \\
(2)Mach-IV & $.70^{*}$ & $.78^{*}$ & & \\
(3)Primary Psychopathy & $.66^{*}$ & $.81^{*}$ & $.85^{*}$ & $.67^{*}$ \\
(4)Secondary Psychopathy & $.48^{*}$ & -.08 & $.55^{*}$ & .17 \\
\hline
\end{tabular}

Note. ${ }^{*} p<.01$, two-tailed.

These results suggest that the female subjects have the psychopathy-like temperament that is most likely related to genetics (primary psychopathy), but do not show the common antisocial behavior that is associated with socializing influences (secondary psychopathy). Antisocial behavior is characterized by impulsivity, aggression, frustration and common boredom (Levenson et al., 1995). These characteristics are stereotypically associated with males, and the aggressive attitude is common in their socialization. The females in the present study may possess these cold interpersonal traits, but as their secondary psychopathy scores indicate, they do not display them in their behavior. These findings can be interpreted in a number of ways. Socialization of females differs from the ones of males. Indeed, females are typically discouraged from behaving in an antisocial manner and going against the societal norms (Maccoby, 1986). Due to females' typical socialization and role expectations, it is possible that females learned to suppress and not demonstrate these cold attitudes (Levenson et al., 1995). Another interpretation of the current findings is related to one of the leading characteristics of both psychopathy and Machiavellianism: aggression. Aggression is one of the antisocial behaviors that is mostly associated with male behavior. While females also display aggressive tendencies, it is possible that the difference in scores stem from the different methods of aggression. Prior research investigated the type of aggression used by females, and concluded that females are most likely to use covert forms of aggression instead of open forms, which are used by males (Björkqvist, Österman, \& Kaukiainen, 1992). The present results could be explained by the inability of the SRPS to assess covert forms of aggression and their extensive focus on open aggression, creating a gender bias.

\section{Conclusion}

This study aimed to investigate the parent behavior's effect on two personality traits, Machiavellianism and secondary psychopathy by focusing on the parental rejection and overprotection factors. Simultaneously, this study investigated the relationship between Machiavellianism and the subtypes of psychopathy, alongside the influence of gender. Our results were not able to provide evidence regarding a link between parental behavior and psychopathy or 
Machiavellianism. However, a positive correlation was found between primary psychopathy and Machiavellianism for males and females, as well as a positive correlation between secondary psychopathy and Machiavellianism for males only.

The present study had a few limitations. First, the population was nonclinical; therefore, only a few individuals scored high on the Machiavellian and psychopathy scales. Second, the sEMBU questionnaire is a retrospective evaluation, which heavily relies on participants' childhood memories. Third, all the present measurements are self-report questionnaires. This leads to the assumption that the individuals' scores relied heavily on how accurately they can see themselves and how they wanted to portray themselves as well. The socially desirable responding is almost impossible to control, and it makes the scores susceptible for faking good or bad responses (Brinkley et al., 2001). Thus, the non-Machiavellian and non-psychopathic responding could be an indicator for socially desirable responding. Finally, future studies should opt for alternative questionnaires assessing psychopathy, such as the Psychopathic Personality Inventory (Lilienfeld \& Andrews, 1996). The PPI assesses psychopathy on eight personality traits, which could give better results for a community sample, as it does not focus on criminal behaviors (Patrick, Fowles, \& Krueger, 2009).

Overall, the current results emphasize the importance to conduct gender-based analysis on studies related to the Dark Triad, as different tendencies can emerge for males or females exclusively. A deeper understanding of the role of psychopathy and Machiavellianism for each gender might be necessary before attempting to conduct future studies on the role of parental behaviors in the emergence of personality traits related to the Dark Triad.

\section{Funding and conflict of interests}

This research did not receive any specific grant from funding agencies in the public, commercial, or not-for-profit sectors. No authors report any conflicts of interests.

\section{References}

Ali, F., \& Chamorro-Premuzic, T. (2010). The dark side of love and life satisfaction: Associations with intimate relationships, psychopathy and Machiavellianism. Personality and Individual Differences, 48(2), 228-233. http://doi.org/10.1016/j.paid.2009.10.016

Allsopp, J., Eysenck, H. J., \& Eysenck, S. B. G. (1991). Machiavellianism as a component in psychoticism and extraversion. Personality and Individual Differences, 12(1), $29-41$. http://doi.org/10.1016/0191-8869(91)90129-Y

Arrindell, W. A., Sanavio, E., Aguilar, G., Sica, C., Hatzichristou, C., Eisemann, M., ... Van Der Ende, J. (1999). The development of a short form of the EMBU 1: Its appraisal with students in Greece, Guatemala, Hungary and Italy. Personality and Individual Differences, 27(4), 613-628. http://doi.org/10.1016/S0191-8869(98)00192-5 
Arrindell, W. a, Richter, J., Eisemann, M., Gärling, T., Rydén, O., Hansson, S. B., ... Gustafsson, M. (2001). The short-EMBU in East-Germany and Sweden: a cross-national factorial validity extension. Scandinavian Journal of Psychology, 42(2), 157-160. http://doi.org/10.1111/14679450.00226

Belsky, J., Steinberg, L., \& Draper, P. (1991). Childhood experience, interpersonal development, and reproductive strategy: and evolutionary theory of socialization. Child Development, 62(4), 647670. http://doi.org/10.1111/1467-8624.ep9109162242

Berg, J. M., Smith, S. F., Watts, A. L., Ammirati, R., Green, S. E., \& Lilienfeld, S. O. (2013).

Misconceptions regarding psychopathic personality: implications for clinical practice and research. Neuropsychiatry, 3, 63-74. http://doi.org/10.2217/npy.12.69

Björkqvist, K., Österman, K., \& Kaukiainen, A. (1992). The development of direct and indirect aggressive strategies in males and females. Retrieved from http://psycnet.apa.org/psycinfo/1992-98493-005

Brinkley, C. A., Schmitt, W. A., Smith, S. S., \& Newman, J. P. (2001). Construct validation of a selfreport psychopathy scale: Does Levenson's self-report psychopathy scale measure the same constructs as Hare's psychopathy checklist-revised? Personality and Individual Differences, 31(7), 1021-1038. http://doi.org/10.1016/S0191-8869(00)00178-1

Christie, R., \& Geis, F. (1970). Studies in Machiavellianism. London: Academic Press.

Cleckley, H. (1941). The mask of sanity; an attempt to reinterpret the so-called psychopathic personality. Jama, 117(6), 493. http://doi.org/10.1001/jama.1941.02820320085028

Dahling, J. J., Whitaker, B. G., \& Levy, P. E. (2008). The Development and Validation of a New Machiavellianism Scale. Journal of Management, 35(2), 219-257. http://doi.org/10.1177/0149206308318618

Fite, P. J., Greening, L., \& Stoppelbein, L. (2008). Relation between parenting stress and psychopathic traits among children. Behavioral Sciences $\mathcal{E}$ the law, 26(2), 239-248.

Frick, P. J., Bodin, S. D., \& Barry, C. T. (2000). Psychopathic traits and conduct problems in community and clinic-referred samples of children: further development of the psychopathy screening device. Psychological Assessment, 12(4), 382-93. http://doi.org/10.1037/10403590.12.4.382

Hall, J., \& Benning, S. (2006). The "successful” psychopath: adaptive and subclinical manifestations of psychopathy in the general population. In C. J. Patrick (Ed.), Handbook of psychopathy (Guilford P, pp. 459-478). NY, USA.

Hare, R. D. (1991). The Hare Psychopathy Checklist-revised (MultiHealt). Toronto.

Hare, R. D. (2003). The Hare Psychopathy Checklist- Revised. Muliti-Health Systems.

Harpur, T. J., Hare, R. D., \& Hakstian, A. R. (1989). Two-factor conceptualization of psychopathy: Construct validity and assessment implications. Psychological Assessment, 1, 6-17. http://doi.org/10.1037//1040-3590.1.1.6 
Hart, S., \& Hare, R. (1998). Association between psychopathy and narcissism: Theoretical views and empirical evidence. Disorders of Narcissism: Diagnostic, Clinical, and empirical implications 415436.

Hicks, B. M., Carlson, M. D., Blonigen, D. M., Patrick, C. J., Iacono, W. G., \& MGue, M. (2012). Psychopathic personality traits and environmental contexts: Differential correlates, gender differences, and genetic mediation. Personality Disorders: Theory, Research, and Treatment, 3(3), 209-227. http://doi.org/10.1037/a0025084

Jonason, P. K., \& Webster, G. D. (2010). The dirty dozen: A concise measure of the dark triad. Psychological Assessment, 22(2), 420-432. http://doi.org/10.1037/a0019265

Karpman, B. (1941). On the need of separating psychopathy into two distinct clinical types: the symptomatic and the idiopathic. Journal of Criminal Psychopathology.

Klonsky, E. D., Oltmanns, T. F., Turkheimer, E., \& Fiedler, E. R. (2000). Recollections of conflict with parents and family support in the personality disorders. Journal of Personality Disorders, 14(4), 327-38. http://doi.org/10.1521/pedi.2000.14.4.327

Kraut, R. E., \& Price, D. J. (1976). Machiavellianism in Parents and Their Children. Journal of Personality and Social Psychology, 33(6), 782-786. http://doi.org/10.1037//0022-3514.33.6.782

Lee, Z., \& Salekin, R. T. (2010). Psychopathy in a noninstitutional sample: Differences in primary and secondary subtypes. Personality Disorders: Theory, Research, and Treatment, 1(3), 153-169. http://doi.org/10.1037/a0019269

Levenson, M. R., Kiehl, K. A., \& Fitzpatrick, C. M. (1995). Assessing Psychopathic Attributes in a Noninstitutionalized Population. Journal of Personality and Social Psychology, 68(1), 151-158. Retrieved from http://www.ncbi.nlm.nih.gov/pubmed/23462286

Lilienfeld, S. O., \& Andrews, B. P. (1996). Development and Preliminary Validation of a Self-Report Measure of Psychopathic Personality Traits in Noncriminal Populations. Journal of Personality Assessment, 66(3), 488-524. http://doi.org/10.1207/s15327752jpa6603_3

Lilienfeld, S. O., \& Hess, T. H. (2001). Psychopathic personality traits and somatization: Sex differences and the mediating role of negative emotionality. Journal of Psychopathology and Behavioral Assessment, 23(1), 11-24. http://doi.org/10.1023/A:1011035306061

Maccoby, E. (1986). Social groupings in childhood: Their relationship to prosocial and antisocial behavior in boys and girls. Development of Antisocial and Prosocial Behavior: Research, theories, and issues, 263-284.

Marshall, L. A., \& Cooke, D. J. (1999). The Childhood Experiences of Psychopaths: A Retrospective Study of Familial and Societal Factors. Journal of Personality Disorders, 13(3), 211-225. http://doi.org/10.1521/pedi.1999.13.3.211

Mealey, L. (1995). The sociobiology of sociopathy: An integrated evolutionary model. Behavioral and Brain Sciences, 18(3), 523-541. http://doi.org/10.1017/S0140525X00039595

Patrick, C. J., Fowles, D. C., \& Krueger, R. F. (2009). Triarchic conceptualization of psychopathy: 
Developmental origins of disinhibition, boldness, and meanness. Development and Psychopathology, 21(3), 913. http://doi.org/10.1017/S0954579409000492

Patterson, J. M. (1988). Families experiencing stress. Family Systems Medicine, 6(2), $202-237$. http://doi.org/10.1037/h0089739

Paulhus, D. L., Neumann, C. S., \& Hare, R. D. (2010). Manual for the Self-Report Psychopathy Scale (SRP-III). Toronto: Multi-Health Systems.

Paulhus, D. L., \& Williams, K. M. (2002). The Dark Triad of personality: Narcissism, Machiavellianism, and psychopathy. Journal of Research in Personality, 36(6), 556-563. http://doi.org/10.1016/S0092-6566(02)00505-6

Ray, J. V., Weir, J. W., Poythress, N. G., \& Rickelm, A. (2011). Correspondence Between the Psychopathic Personality Inventory and the Psychopathic Personality Inventory-Revised: a Look At Self-Reported Personality Traits. Criminal Justice and Behavior, 38(4), 375-385. http://doi.org/10.1177/0093854811398178

Robins, L. (1966). DEVIANT CHILDREN GROWN UP, A SOCIOLOGICAL AND PSYCHIATRIC STUDY OF SOCIOPATHIC PERSONALITY. Retrieved from http://eric.ed.gov/?id=ED018885

Saltaris, C. (2002). Psychopathy in juvenile offenders - Can temperament and attachment be considered as robust developmental precursors? Clinical Psychology Review, 22(5), 729-752. http://doi.org/10.1016/S0272-7358(01)00122-2

Sutton, J., \& Keogh, E. (2001). Components of Machiavellian beliefs in children: Relationships with personality. Personality and Individual Differences, 30(1), 137-148. http://doi.org/10.1016/S01918869(00)00017-9

Vernon, P., Villani, V., Vickers, L., \& Harris, J. (2008). A behavioral genetic investigation of the Dark Triad and the Big 5. Personality and Individual Differences,44(2), 445-452.

Williams, K., \& Paulhus, D. (2004). Factor structure of the Self-Report Psychopathy scale (SRP-II) in non-forensic samples. Personality and Individual Differences, 37(4), 765-778. 